\title{
The influence of organizational commitment on the perceived effectiveness of virtual meetings by Filipino professionals during the COVID-19 pandemic: A structural equation modeling approach
}

\author{
Yogi Tri Prasetyo ${ }^{\mathrm{a}, *}$, Lorenzo Dones Montenegro ${ }^{\mathrm{a}, \mathrm{b}, \mathrm{c}}$, Reny Nadlifatin ${ }^{\mathrm{d}}$, Yoshiki B. Kurata ${ }^{\mathrm{a}, \mathrm{b}, \mathrm{e}}$, \\ Ardvin Kester S. Ong ${ }^{\mathrm{a}, \mathrm{b}, \mathrm{e}}$ and Thanatorn Chuenyindee ${ }^{\mathrm{a}, \mathrm{b}, \mathrm{f}}$ \\ ${ }^{a}$ School of Industrial Engineering and Engineering Management, Mapúa University, Manila, Philippines \\ ${ }^{\mathrm{b}}$ School of Graduate Studies, Mapúa University, Manila, Philippines \\ ${ }^{\mathrm{c}}$ Department of Arts \& Letters, Mapúa University, Manila, Philippines \\ ${ }^{\mathrm{d}}$ Department of Information Systems, Kampus ITS Sukolilo, Institut Teknologi Sepuluh Nopember, Surabaya, \\ Indonesia \\ ${ }^{\mathrm{e}}$ Department of Industrial Engineering, Faculty of Engineering, University of Santo Tomas, Manila, Philippines \\ ${ }^{\mathrm{f}}$ Department of Industrial Engineering and Aviation Management, Navaminda Kasatriyadhiraj Royal Air Force \\ Academy, Bangkok, Thailand
}

Received 15 January 2021

Accepted 16 September 2021

\begin{abstract}
.
BACKGROUND: Virtual meetings have been widely utilized during the COVID-19 pandemic.

OBJECTIVE: The purpose of this study was to explore the influence of organizational commitment on the perceived effectiveness of virtual meeting by Filipino professionals during the COVID-19 pandemic.

METHODS: A total of 513 Filipino professionals answered an online questionnaire which covered four latent variables: organizational commitment to virtual meetings, attitude toward virtual meetings, perceived effectiveness of virtual meeting as collaboration tool, and perceived effectiveness of virtual meeting as a social tool. Structural Equation Modeling (SEM) was utilized to analyze the causal relationships between the latent variables construct.

RESULTS: SEM showed that organizational commitment to virtual meeting during the COVID-19 pandemic influenced the positive attitude of the employees which subsequently led to the perceived effectiveness of virtual meeting as a collaboration and social tool.

CONCLUSIONS: This study is the first study that analyzed the influence of organizational commitment on the perceived effectiveness of virtual meeting during the COVID-19 pandemic in the Philippines. Our SEM construct can be applied and extended further, particularly in analyzing factors influencing the perceived effectiveness of virtual meeting during the COVID-19 pandemic.
\end{abstract}

Keywords: Coronavirus, COVID-19, online meeting, employee attitudes, perceived usefulness, mediator effect

\section{Introduction}

*Address for correspondence: Yogi Tri Prasetyo, 658 Muralla St., Intramuros, Manila 1002, Philippines. E-mail: ytprasetyo@ mapua.edu.ph.
The COVID-19 pandemic has changed the human behavior in information technology. As of September 9 th 2021 , there have been $222,406,582$ confirmed 
cases of COVID-19, including 4,592,934 deaths [1], making governments worldwide to impose lockdown and aggressive restriction measures such as work-from-home (WFH). Various information technology sectors, businesses, and organizations around the world have also shown their cooperation by modifying their business operations and providing flexible services among its employees through several platforms. One of the most commonly information technology platforms that widely utilized during the COVID-19 pandemic is virtual meeting.

Virtual meetings are a form of communication technology perceived as a fundamental tool for work by organizations, particularly in keeping people connected and in establishing a virtual shared space [2]. It provides a platform for people to stay connected despite the physical and geographical constraints imposed by the government due to the COVID-19 pandemic. Several platforms such as Zoom and Google Meet have been widely utilized in various virtual meetings or virtual recruitment in different business to keep organizations and employees continue the work despite the challenges brought by COVID-19 pandemic [3]. Moreover, virtual meeting has also been utilized by hospitals and health facilities in holding health advising and counseling sessions. The most important consideration for virtual meeting, however, is making sure that every person has the communication facilities and devices for running and establishing virtual meetings [4].

Previously, there were several studies related to virtual meetings' impacts on different organizations in several countries even before the COVID-19 pandemic. In Sweden, the national government supports the use of virtual meetings as it was found to reduce travel costs, reduce environmental impacts, increase business mobility, increase collaboration, and improve productivity of the employees [5]. In South Korea, Choi and Cho [6] found that coordination and cooperation in virtual teams with strong autonomy improve knowledge sharing were crucial aspects in collaborative functions, particularly as tasks or projects become more complex. Finally, in Taiwan, Chumg et al. [7] stated that the absence of physical contact and proximity gives employees a greater sense of responsibility for cooperation and coordination. Thus, virtual meetings mostly perceived as a good platform in which the organizations can practice and enhance their cultural intelligence [8].

Cultural intelligence contributes to the collaboration and coordination benefits in the organizations that operate on a global scale. In the Philippines, where global call and business process outsourcing (BPO) centers are commonly based, it was found that cultural intelligence promotes task performance, especially those that are accomplished through cross-cultural teams [9]. Since the interaction and collaboration among cross-cultural virtual teams are done and established over virtual meetings, employees become more culturally aware of their respective organizations' and counterparts' diverse backgrounds [8].

Despite the availabilities of many studies related to virtual meeting as a new platform during the COVID19 pandemic, few studies highlighted the influence of organizational commitment on the perceived effectiveness of virtual meeting during the COVID-19 pandemic (Table 1). Most of the recent studies suggested several research directions such as exploring the organizational impacts of virtual meetings during the COVID-19 pandemic on various settings

Table 1

Research gaps

\begin{tabular}{lll}
\hline Research gaps & Suggested research direction & References \\
\hline $\begin{array}{l}\text { Organizational impacts of } \\
\text { virtual meetings during }\end{array}$ & $\begin{array}{l}\text { Explore the organizational impacts of virtual } \\
\text { meetings during COVID-19 on various } \\
\text { seVID-19 }\end{array}$ & {$[3,10,11]$} \\
$\begin{array}{l}\text { Organizational effects on } \\
\text { other settings }\end{array}$ & $\begin{array}{l}\text { Conduct research on other local settings, } \\
\text { even on a global scale }\end{array}$ & {$[5,16]$,} \\
$\begin{array}{l}\text { Factors that affect the } \\
\text { effectiveness of virtual } \\
\text { meetings }\end{array}$ & $\begin{array}{l}\text { Explore the impacts of certain aspects within } \\
\text { the organizational sphere on the use of } \\
\text { virtual meetings }\end{array}$ & {$[6,7,12]$} \\
$\begin{array}{l}\text { Lack of studies on } \\
\text { human- machine } \\
\text { interaction on virtual } \\
\text { meetings }\end{array}$ & $\begin{array}{l}\text { Focused research on human-machine } \\
\text { interaction }\end{array}$ & {$[2,17]$} \\
$\begin{array}{l}\text { Dominated by studies on } \\
\text { organizational virtual }\end{array}$ & $\begin{array}{l}\text { Examine the capability and effectiveness of } \\
\text { meeting systems }\end{array}$ & $\begin{array}{l}\text { other communication technologies such as } \\
\text { social media applications }\end{array}$ \\
\hline
\end{tabular}


$[3,10,11]$ and exploring the impacts of certain aspects within the organizational sphere on the use of virtual meetings $[6,7,12]$. Moreover, as one of the most countries with the most active cases of COVID19 in the world, very few studies have been done in the Philippines particularly related to the virtual meeting. Most studies only focused on the clinical [13], perceived effectiveness of COVID-19 prevention measures [14], or COVID-19 model estimation [15]. Thus, it is valuable to analyze another impact of COVID-19 in the Philippines particularly related to the virtual meeting.

The purpose of this study was to explore the influence of organizational commitment on the perceived effectiveness of virtual meeting by Filipino professionals during the COVID-19 pandemic. Different from our previous study which mainly focused on the perceived effectiveness of COVID-19 prevention measures by the Philippines government [14], this study highlighted the important of virtual meeting as collaboration and social tool which supported by the organizational commitment. This study is one of the first study that analyzed the influence of organizational commitment on the perceived effectiveness of virtual meeting during the COVID-19 pandemic in the Philippines. Our structural equation modeling (SEM) construct can be applied and extended further, particularly in analyzing factors influencing the perceived effectiveness of virtual meeting or other platforms during the COVID-19 pandemic.

\section{Research model and hypotheses}

We came up with a straightforward research model that fits the hypotheses developed in this study. Since the implementation of the use of virtual meetings was an organizational initiative, the model started from an organizational-level influence going forward to individual- level perception which subsequently led to the perceived effectiveness of virtual meeting (Fig. 1).

The structural research model started from an organizational level of influence with organizational commitment to virtual meetings. Chumg et al. [7] showed that organizational culture promotes and influences collaboration among employees. It was also found that an organization's eagerness and support toward virtual collaborations contribute to strengthened collaboration among employees [19]. These led to the first hypothesis:

H1. Organizational commitment to virtual meetings had a significant effect on employees' attitudes toward virtual meetings.

Moving forward to an individual level of influence, the structural research model put employees' attitudes toward virtual meetings in the center as the mediating factor that directly influenced perceived effectiveness. Their attitudes which covered how they perceived the virtual meetings' usefulness in their work and utility in providing social connection despite physical constraint, how they inclined to the actual use of virtual meetings, and how usable of these technologies for them.

Finally, the final output of the model construct was the perceived effectiveness of virtual meeting. Aside from knowing the respondents' perceived effectiveness of virtual meeting as a collaboration tool, the study also aimed to explore the respondents' perceived effectiveness of virtual meeting as a social tool during the COVID-19 pandemic as the World Health Organization [1] consistently reiterates the relevance of keeping a community and an organization socially

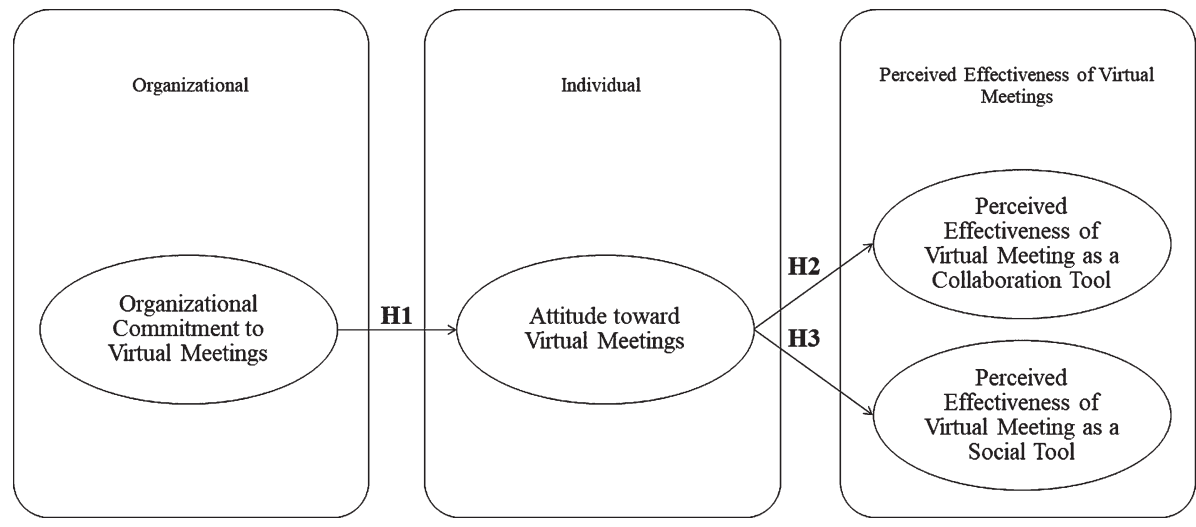

Fig. 1. The research model and hypotheses construct. 
connected during this time. Thus, these considerations led to the second and third hypotheses:

H2. Employees' attitudes toward virtual meetings had a significant effect on their perceived effectiveness of virtual meetings as a collaboration tool.

H3. Employees' attitudes toward virtual meetings had a significant effect on their perceived effectiveness of virtual meetings as a social tool.

\section{Methodology}

\subsection{Participants}

This study was approved by the School of Industrial Engineering and Engineering Management Mapua University Research Ethics Committees. A total of 513 Filipino professionals from different organizations and area of work voluntary participated in the current study (Table 2). $70 \%$ respondents were female, $29 \%$ respondents were male, and only one percent $(1 \%)$ preferred not to disclose their gender. The youngest respondent was 19 years old while the oldest was 73 years old, giving a mean age of 32 years old (Std: 10.31). Half of the respondents (50\%) had experiences of 1-5 years in their respective organizations, followed by $11-$ more years (21\%), 6-10 years $(17 \%)$ and lastly, less than 1 year (13\%). Finally, the area or sphere where most respondents (39\%) work was Education, followed by Customer Service (22\%), Commerce (7\%) and Industry (7\%), Software (5\%) then Marketing (4\%), while the rest of the respondents $(16 \%)$ were from other areas of work.

\subsection{Questionnaire}

Following our previous studies [20, 21], a survey questionnaire delivered online and in English was used to gather data from the respondents. The questionnaire consisted of multiple choice and rating items which gave answers on the organizational commitment to virtual meetings, the respondents' attitudes toward virtual meetings, and the respondents' perceptions on the effectiveness of virtual meetings as a collaboration and social tool. A 5-point Likert scale: 5 - strongly agree, 4 - agree, 3 - neutral, 2 - disagree and 1 - strongly disagree was used for the rating items. Table 3 represents the summary of questions included in the quantitative measurement instrument.

\subsection{Data collection}

This survey was conducted online during the General Community Quarantine (GCQ) in the Philippines from October 1st to December 18th, 2020 through Google Forms. The survey questionnaire consisted of an introductory section with a brief explanation the purpose of the study, the demographic part, and

Table 2

Demographic profile of respondents $(n=513)$

\begin{tabular}{|c|c|c|c|}
\hline Variable & Categories & Frequency & $\%$ \\
\hline \multirow{3}{*}{ Gender } & Female & 360 & 70.2 \\
\hline & Male & 146 & 28.5 \\
\hline & Prefer not to say & 7 & 1.4 \\
\hline \multirow[t]{5}{*}{ Age } & 16-25 years old & 184 & 35.9 \\
\hline & 26-35 years old & 169 & 32.9 \\
\hline & $36-45$ years old & 87 & 17.0 \\
\hline & $46-55$ years old & 51 & 9.9 \\
\hline & 56 years old (Over) & 22 & 4.3 \\
\hline \multirow[t]{4}{*}{ Working years } & Less than 1 year & 66 & 12.9 \\
\hline & $1-5$ years & 254 & 49.5 \\
\hline & $6-10$ years & 87 & 17.0 \\
\hline & 11-more years & 106 & 20.7 \\
\hline \multirow[t]{7}{*}{ Area of work } & Education & 198 & 38.6 \\
\hline & $\begin{array}{l}\text { Customer Service (Call } \\
\text { center, shared services) }\end{array}$ & 114 & 22.2 \\
\hline & $\begin{array}{l}\text { Commerce (retail, banking, } \\
\text { finance) }\end{array}$ & 38 & 7.4 \\
\hline & $\begin{array}{l}\text { Industry (manufacturing, } \\
\text { design, production) }\end{array}$ & 38 & 7.4 \\
\hline & Software, IT & 27 & 5.3 \\
\hline & Marketing, advertising & 19 & 3.7 \\
\hline & Other & 79 & 15.4 \\
\hline
\end{tabular}


Table 3

The item constructs and measures

\begin{tabular}{|c|c|c|}
\hline Item & Measures & Reference \\
\hline$\overline{\mathrm{OC}} 1$ & $\begin{array}{l}\text { My organization is open to virtual collaborations and virtual } \\
\text { environments during the COVID- } 19 \text { pandemic. }\end{array}$ & [22] \\
\hline $\mathrm{OC} 2$ & $\begin{array}{l}\text { My organization supports the use of virtual meetings for work-related } \\
\text { purposes during the COVID-19 pandemic. }\end{array}$ & \\
\hline $\mathrm{OC} 3$ & $\begin{array}{l}\text { My organization provides the tools and facilities for virtual meetings } \\
\text { and environments during the COVID-19 pandemic. }\end{array}$ & {$[22]$} \\
\hline $\mathrm{OC} 4$ & $\begin{array}{l}\text { My organization provides excellent information and resources with } \\
\text { regard virtual meeting systems during the COVID-19 pandemic. }\end{array}$ & [24] \\
\hline OC5 & $\begin{array}{l}\text { My organization supports the use of virtual meetings for non-work } \\
\text { related purposes (e.g. social interaction and activities) during the } \\
\text { COVID-19 pandemic. }\end{array}$ & {$[25]$} \\
\hline A1 & $\begin{array}{l}\text { Virtual meetings are useful in my professional role during the } \\
\text { COVID-19 pandemic. }\end{array}$ & [16] \\
\hline A2 & In general, virtual meetings during the COVID-19 pandemic work well. & \\
\hline A3 & Virtual meetings during the COVID-19 pandemic are easy to use. & {$[22]$} \\
\hline A4 & $\begin{array}{l}\text { I can manage technologies/systems for virtual meetings well during the } \\
\text { COVID-19 pandemic. }\end{array}$ & [16] \\
\hline A5 & $\begin{array}{l}\text { I am glad to share my work reports and presentations with colleagues } \\
\text { through virtual meetings during the COVID- } 19 \text { pandemic. }\end{array}$ & [7] \\
\hline A6 & $\begin{array}{l}\text { I am pleased to share official documents through virtual meetings } \\
\text { during the COVID-19 pandemic. }\end{array}$ & [7] \\
\hline A7 & $\begin{array}{l}\text { I will share multimedia files such as media, context, picture or video } \\
\text { with colleagues through virtual meetings during the COVID-19 } \\
\text { pandemic. }\end{array}$ & [7] \\
\hline A8 & I prefer virtual meetings over in-person meetings. & \\
\hline PEC1 & $\begin{array}{l}\text { All meeting agenda, questions and concerns get accomplished and } \\
\text { addressed during virtual meetings. }\end{array}$ & \\
\hline PEC2 & $\begin{array}{l}\text { Virtual meeting during the COVID-19 pandemic is an effective } \\
\text { platform for discussing group functions such as projects and other } \\
\text { team collaborations. }\end{array}$ & {$[25]$} \\
\hline PEC3 & $\begin{array}{l}\text { Virtual meeting during the COVID-19 pandemic is an effective } \\
\text { platform for disseminating information on organizational updates, } \\
\text { memorandums, etc. }\end{array}$ & \\
\hline PEC4 & $\begin{array}{l}\text { Virtual meeting during the COVID-19 pandemic is an effective } \\
\text { platform for trainings and workshops. }\end{array}$ & {$[18]$} \\
\hline PEC5 & $\begin{array}{l}\text { I am able to present my work reports to colleagues and seniors } \\
\text { successfully during COVID- } 19 \text { pandemic. }\end{array}$ & \\
\hline PEC6 & $\begin{array}{l}\text { I am able to give inputs during discussions and open forums on virtual } \\
\text { meetings during the COVID- } 19 \text { pandemic. }\end{array}$ & \\
\hline PEC7 & $\begin{array}{l}\text { Virtual meetings during the COVID- } 19 \text { pandemic provide the same } \\
\text { level of collaboration as in- person meetings. }\end{array}$ & [13] \\
\hline PEC8 & $\begin{array}{l}\text { Virtual meeting has been a more valuable collaboration tool during } \\
\text { COVID-19. }\end{array}$ & \\
\hline PES1 & $\begin{array}{l}\text { Virtual meetings during the COVID-19 pandemic keep employees } \\
\text { socially connected. }\end{array}$ & {$[4]$} \\
\hline PES2 & $\begin{array}{l}\text { Virtual meetings during the COVID-19 pandemic expand my social } \\
\text { network in the organization. }\end{array}$ & \\
\hline PES3 & $\begin{array}{l}\text { I share personal stories and experiences on virtual meetings during the } \\
\text { COVID-19 pandemic. }\end{array}$ & [24] \\
\hline PES4 & $\begin{array}{l}\text { I get to know my colleagues personally on virtual meetings during the } \\
\text { COVID-19 pandemic. }\end{array}$ & {$[23]$} \\
\hline PES5 & $\begin{array}{l}\text { I share and get updates on current events and news on virtual meetings } \\
\text { during the COVID- } 19 \text { pandemic. }\end{array}$ & {$[23]$} \\
\hline PES6 & $\begin{array}{l}\text { I am active during casual conversations on virtual meetings during the } \\
\text { COVID-19 pandemic. }\end{array}$ & {$[23]$} \\
\hline PES7 & $\begin{array}{l}\text { Virtual meetings during the COVID- } 19 \text { pandemic provide the same } \\
\text { level of social interaction as physical interactions. }\end{array}$ & {$[24]$} \\
\hline PES8 & Virtual meeting has been a more valuable social tool during COVID- 19 . & {$[25]$} \\
\hline
\end{tabular}

Note 1. $\mathrm{OC}=$ Organizational Commitment, $\mathrm{A}=$ Attitude, $\mathrm{PEC}=$ Perceived Effectiveness as a Collaboration Tool, PES $=$ Perceived Effectiveness as a Social Tool 
the main section which consisted of 29 questions. The link to the survey was sent personally to some respondents and posted on organizational pages, various groups on Facebook, and LinkedIn to gather more respondents.

\subsection{Statistical analysis}

SEM using AMOS 24 was utilized to analyze the proposed hypotheses of this study. Following our previous studies that utilized SEM [14, 20, 21], six measurement indices were used to analyze the model: Incremental Fit Index (IFI), Tucker Lewis Index (TLI), Comparative Fit Index (CFI), Goodness of Fit Index (GFI), Adjusted Goodness of Fit Index (AGFI), Root Mean Square Error of Approximation (RMSEA). These measurement indices were the bases for the model fit for the data tested in this study [26].

\section{Results}

Figure 2 represents the SEM for evaluating the influence of organizational commitment on the perceived effectiveness of virtual meeting by Filipino professionals during the COVID-19 pandemic. The results showed that organizational commitment to virtual meetings $(\beta=0.47)$ positively influenced employees' attitudes toward virtual meetings which subsequently influenced employees' perceived effectiveness of virtual meeting as a collaboration tool $(\beta=0.88)$ and as a social tool $(\beta=0.62)$.

Table 4 represents the details of the mean, standard deviation, and the factor loading for each indicator. As recommended by Hair, (2010), the factor loading should be higher or approaching to 0.7 . There were 4 indicators which had factor loadings lower than 0.6 : OC5 (0.471), A8 (0.572), PEC8 (0.593), and PES8 (0.552). Thus, we decided to eliminate these 4 indicators.

Table 5 represents the model fit of the SEM construct. Based on this table, IFI, TLI, and CFI values were $0.924,0.910$, and 0.923 respectively, indicating that the model passed the suggested cut-off of 0.90 [26]. In addition, the GFI and AGFI values were 0.866 and 0.831 respectively, indicating that the model was also good [26]. Finally, the RMSEA value was 0.071 which also lower than the suggested cut-off of 0.80 [27], indicating that the model was a good representation of the observed data.

\section{Discussion}

Virtual meetings have been widely utilized during the COVID-19 pandemic. The purpose of this study was to explore the influence of organizational commitment on the perceived effectiveness of virtual meeting by Filipino professionals during the COVID-19 pandemic. A total of 513 Filipino professionals answered an online questionnaire which covered four latent variables: organizational commitment to virtual meetings, attitude toward virtual meetings, perceived effectiveness of virtual meeting as collaboration tool, and perceived effectiveness of virtual meeting as a social tool. This study highlighted the important of virtual meeting as collaboration and social tool which supported by the organizational commitment.

With a path coefficient of $0.47, \mathrm{H1}$ was supported, thus an organizational level influence such as

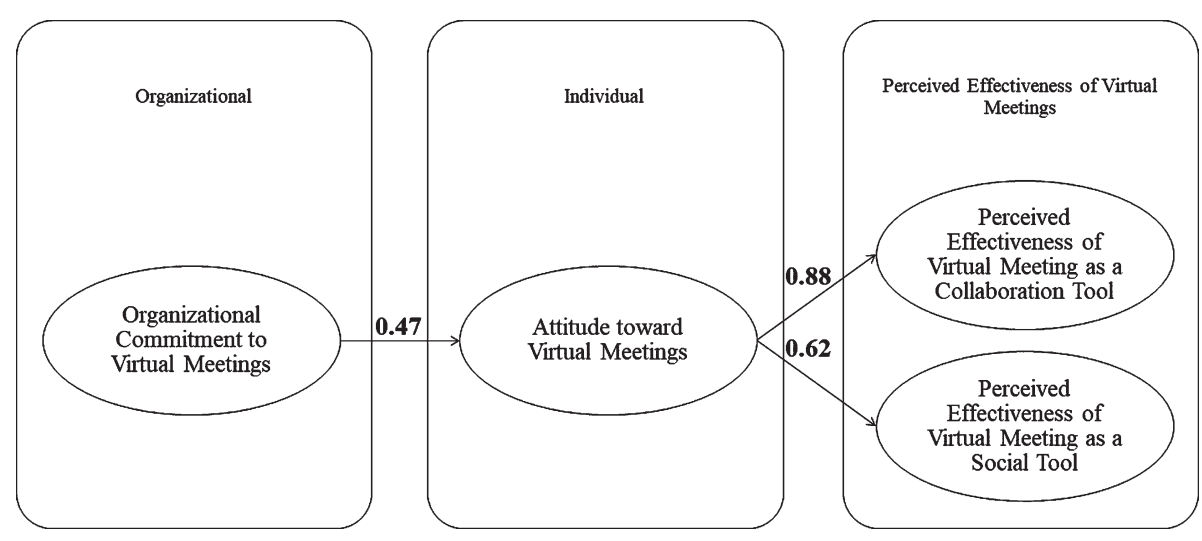

Fig. 2. Analysis of direct effects in the structural research model. 
Table 4

The relevant analytic values of the measurement model of the research

\begin{tabular}{|c|c|c|c|c|}
\hline Constructs & Item & Mean & StD & Loadings* \\
\hline \multirow{5}{*}{$\begin{array}{l}\text { Organizational commitment } \\
\quad(\text { Composite mean score }=4.61)\end{array}$} & $\mathrm{OC} 1$ & 4.71 & 0.604 & $0.892^{*}$ \\
\hline & $\mathrm{OC} 2$ & 4.76 & 0.541 & $0.902^{*}$ \\
\hline & OC3 & 4.49 & 0.805 & $0.620^{*}$ \\
\hline & OC4 & 4.46 & 0.736 & $0.659^{*}$ \\
\hline & OC5 & 4.21 & 1.012 & 0.471 \\
\hline \multirow{8}{*}{$\begin{array}{l}\text { Attitude } \\
\quad(\text { Composite mean score }=4.46)\end{array}$} & A1 & 4.69 & 0.524 & $0.594^{*}$ \\
\hline & A2 & 4.45 & 0.639 & $0.725^{*}$ \\
\hline & A3 & 4.44 & 0.638 & $0.733^{*}$ \\
\hline & A4 & 4.46 & 0.663 & $0.759^{*}$ \\
\hline & A5 & 4.35 & 0.778 & $0.737^{*}$ \\
\hline & A6 & 4.46 & 0.652 & $0.684^{*}$ \\
\hline & A7 & 4.35 & 0.752 & $0.637^{*}$ \\
\hline & A8 & 3.77 & 1.165 & 0.572 \\
\hline \multirow{8}{*}{$\begin{array}{l}\text { Perceived effectiveness } \\
\text { as a collaboration tool } \\
(\text { Composite mean score }=4.19 \text { ) }\end{array}$} & PEC1 & 4.18 & 0.763 & $0.753^{*}$ \\
\hline & PEC2 & 4.29 & 0.725 & 0.803* \\
\hline & PEC3 & 4.35 & 0.709 & $0.739^{*}$ \\
\hline & PEC4 & 3.93 & 1.001 & $0.674^{*}$ \\
\hline & PEC5 & 4.23 & 0.699 & $0.835^{*}$ \\
\hline & PEC6 & 4.24 & 0.686 & $0.829^{*}$ \\
\hline & PEC7 & 3.71 & 1.110 & $0.717^{*}$ \\
\hline & PEC8 & 4.57 & 0.612 & 0.593 \\
\hline \multirow{8}{*}{$\begin{array}{l}\text { Perceived effectiveness } \\
\text { as a social tool } \\
(\text { Composite mean score }=3.91 \text { ) }\end{array}$} & PES1 & 4.43 & 0.656 & $0.633^{*}$ \\
\hline & PES2 & 4.20 & 0.823 & $0.704^{*}$ \\
\hline & PES3 & 3.76 & 1.027 & $0.796^{*}$ \\
\hline & PES4 & 3.72 & 1.010 & $0.831^{*}$ \\
\hline & PES5 & 4.06 & 0.879 & $0.782^{*}$ \\
\hline & PES6 & 3.81 & 0.901 & $0.832^{*}$ \\
\hline & PES7 & 3.37 & 1.235 & $0.754^{*}$ \\
\hline & PES8 & 4.49 & 0.699 & 0.552 \\
\hline
\end{tabular}

Note 1. Items (OC5, A8 and PES8) were removed from the instrument due to their lower value of factor loading. Note 2. StD = Standard Deviation, $\mathrm{OC}=$ Organizational Commitment, $\mathrm{A}=$ Attitude, $\mathrm{PEC}=$ Perceived Effectiveness as a Collaboration Tool, $\mathrm{PES}=$ Perceived Effectiveness as a Social Tool. Note $3 .{ }^{*} p<0.001$.

Table 5

Model fit

\begin{tabular}{lccc}
\hline Index & Result & $\begin{array}{c}\text { Recommended } \\
\text { value }\end{array}$ & Suggested by \\
\hline Incremental Fit Index (IFI) & 0.924 & $>0.90$ & {$[26]$} \\
Tucker Lewis Index (TLI) & 0.910 & $>0.90$ & {$[26]$} \\
Comparative Fit Index (CFI) & 0.923 & $>0.90$ & {$[26]$} \\
Goodness of Fit Index (GFI) & 0.866 & $>0.80$ & {$[27]$} \\
Adjusted Goodness of Fit Index (AGFI) & 0.831 & $>0.80$ & {$[27]$} \\
Root Mean Square Error of Approximation & & & $<0.80$ \\
(RMSEA) & 0.071 & {$[26]$} \\
\hline
\end{tabular}

commitment to virtual meetings influence employees' personal attitudes toward virtual meetings. This is in line with the study conducted by Concha et al. [19] on the implementation of a software tool in a virtual organization in Mexico that such collaborative virtual efforts are influenced by organizational culture. In contrast, Chumg et al. [7] pointed out that an innovative organizational culture's influence on an employee on a personal level is insignificant in a study conducted in Taiwan.

Meanwhile, Filipino professionals' attitudes toward virtual meetings positively influenced their perceived effectiveness of virtual meeting as a collaboration tool. With a path coefficient of 0.88 , 
this provided strong support for $\mathbf{H 2}$. An employee's perceived effectiveness of a certain technology, in this case using virtual meetings for collaborative and work-related activities, is highly influenced by his/her individual attitude toward the technology. The high composite mean scores for these two constructs further complement the result for this path in the structural research model. Moreover, this finding is supported by Lindeblad et al. [5], who mentioned that employees tend to highly value virtual meetings as they provide improved collaboration and productivity. This has been evident to various professions, especially now that people are working remotely due to physical distance restrictions posed by the COVID19 pandemic [28].

Although not as high as the path coefficient for the attitudes' influence on virtual meetings' effectiveness as a collaboration tool, Filipino professionals' attitudes toward virtual meeting still positively influenced their perceived effectiveness of virtual meeting as social tool with a path coefficient of 0.62 . Thus, this result supported $\mathbf{H 3}$. The composite mean score for the construct on perceived effectiveness of virtual meeting as a social tool was also not as high as the as compared to perceived effectiveness as a collaboration tool, thus reflecting the path coefficient loadings by attitudes on both constructs. Still considered acceptable, virtual meetings are capable enough of keeping employees socially connected during the COVID-19 pandemic and is line with the findings of Porpiglia et al. [28] in a study on virtual events. Furthermore, the capability of virtual meetings to provide social avenues virtually are supported by their interactive features such as chat, audio and video conferencing.

\subsection{Organizational commitment to virtual meetings}

Items OC1-OC4 showed the Filipino professionals' organizational commitment to using virtual meetings. Overall, the composite mean score for this latent construct was 4.61. This result signifies that most Filipino professionals strongly agreed that their organizations view virtual meeting as an essential organizational tool, especially during the COVID-19 pandemic. In addition, our result shows a positive outlook that organizations are open to and in support of virtual collaborations through virtual meetings. Moreover, the strong organizational commitment to and support on the use of virtual meetings are in line with the drastic rise in the use and utilization of such communication technologies by different types of businesses globally during the COVID-19 pandemic [28].

\subsection{Attitude toward virtual meetings}

The attitudes of employees toward virtual meetings were reflected through items A1-A7. Overall, the composite mean score for the latent construct was 4.46. This latent construct was keen in knowing how inclined employees are to the actual use of virtual meetings. It consisted of statements on how they personally feel about using virtual meetings. This result signifies that Filipino professionals strongly agreed that they are having good experiences using virtual meetings and are actually inclined to use such technologies.

Item $\mathbf{A 1}$ (Virtual meetings are useful in my professional role.) received the highest mean score for this latent construct with 4.69. It clearly shows that employees are inclined to use virtual meetings as they are useful in their respective areas of work, especially now that working from home or remotely has been the new norm in organizations. Although, this finding may already be given for employees who regularly work with global and international counterparts evident in the study of Presbitero $[8,9]$ and those who work in purely virtual organizations [7]. Moreover, people who were not in favor of virtual meetings before may have changed their views as virtual meetings may have been the only channel or mode of delivery in which they could carry their professional tasks and activities out during the COVID-19 pandemic.

\subsection{Perceived effectiveness of virtual meeting as a collaboration tool}

Items PEC1-PEC8 consisted of statements that evaluated Filipino professionals' perceived effectiveness of virtual meeting as a collaboration tool. With a composite mean score of 4.19, Filipino professionals agreed that virtual meetings are effective in providing a platform in which they can collaborate virtually. It shows that virtual meetings are able to deliver different work-related activities effectively. This finding is similar to the past study conducted by Lindeblad et al. [5] concluding that virtual meetings improve collaboration and productivity among employees. The absence of physical distance is also found to contribute in strengthening the sense of cooperation among employees, thus making virtual 
meetings an effective platform for establishing coordination within the organization [7].

It was perceived, however, that virtual meetings do not provide the same level of collaboration as in-person meetings, which was evident to the 3.71 mean score of item PEC7 (Virtual meetings provide the same level of collaboration as in-person meetings.), the lowest mean score for this construct. This finding corresponds to the fact that virtual meetings are not applicable to all types of trainings and workshops as item PEC4 (Virtual meeting is an effective platform for trainings and workshops.) received the second lowest mean score for this construct with 3.93. Learning a particular thing over virtual meetings may be challenging, especially when getting familiar to a certain task or activity that is difficult to demonstrate and observe virtually as compared to being done and witnessed in person.

Another essential finding for this construct is that Filipino professionals strongly agree that virtual meeting has been a more valuable collaboration tool during COVID-19. Item PEC8 (Virtual meeting has been a more valuable collaboration tool during COVID-19.) supported this finding with the highest mean score for this latent construct with 4.57. According to the World Health Organization [1], virtual meetings have allowed capable organizations to still function and run their businesses despite the physical and geographical constraints. Thus, Filipino professionals gave more value to virtual meetings now than before.

\subsection{Perceived effectiveness of virtual meeting as a social tool}

This latent construct focuses more on the effectiveness of virtual meeting as a tool for social interaction, more particularly in carrying non-work related activities out. Items PES1-PES7 had an overall composite mean score of 3.91, not as high as the composite mean score for the virtual meeting's effectiveness as a collaboration tool. Filipino professionals were neutral but leaning toward agreement when it came to their perceived effectiveness of virtual meeting as a social tool. Virtual meeting is not highly regarded as a tool for socializing within organizations, particularly in having casual conversations or other non-work related activities with colleagues.

This finding supported the decision to remove item OB5 (My organization supports the use of virtual meetings for non-work related purposes (e.g. social interaction and activities)) in the measurement model of the research due to low value of factor loading and it does not represent the construct well. It seems that organizations do not strongly agree with the use of virtual meetings as a social tool in the organization. Filipino professionals still prefer in-person meetings when it comes to maintaining social connection and interactions as they gave item PES7 (Virtual meetings provide the same level of social interaction as physical interactions.) the lowest mean score with 3.37 for this construct. However, with a number of features that virtual meetings have such as chat, audio, and video conferencing, they are extremely capable of serving as a platform to keep employees within the organization socially connected. During crises like the COVID-19 pandemic, the World Health Organization [1] has been consistent to its proposition that social connection and communication are vital.

\subsection{Theoretical contributions}

This study contributes to the use of communication technologies in organizations, particularly the use of virtual meetings. First, the study develops a model that evaluates perceived effectiveness of a certain technology based on two levels of influence-organizational and individual. It explores the influence of organizational endeavors on the attitude of and perceived effectiveness by employees toward a technology. The findings of the study supported the notion that an organization's support and commitment to the implementation of a certain technology certainly have impacts on the attitudes of its employees on that particular technology. Concha et al. [19] have already pointed this out in their study, that an organization's eagerness and commitment to implementing new technologies and changes provides strong contribution to the successful practice and use within the organization. Second, the study presents insights on how attitudes toward a certain technology used and deployed in the workplace are partly rooted from an organizational perspective. Employees' attitudes on the acceptance and use of a certain technology is further motivated by how useful it is in their work and in carrying out their professional tasks and activities. Lastly, the study findings provided support to the notion that the attitudes of employees toward the technology translate to their perceived effectiveness. A technology that is both utilized and is strongly supported by the organization and its employees is perceived as an effective organizational tool. 


\subsection{Practical implications}

The study holds relevant practical implications, especially during this era in which various organizational settings have been shifting toward WFH and remote setups. Organizations, particularly decision makers must consider strongly showing their support to the technologies deployed within their respective organizations. Currently, virtual meetings are at the forefront of these technologies as organizations across the globe have been working and collaborating virtually due to the risks posed by the COVID-19 pandemic.

Employees should also leverage and make the most out of these technologies to continue performing in their professional roles and sustain the services of their respective organizations through virtual meetings. Virtual meetings provide an avenue for professionals to collaborate, practice and carry out their work. Aside from work-related use, virtual meetings also allow employees to connect with their colleagues and flourish social connections despite the absence of personal and physical contact, especially during this pandemic. Maintaining social connections is extremely important these times as reiterated by the World Health Organization [1]. These technological capabilities translate to the perceptions and feedback on such technologies. Developers of virtual meetings could make use of the feedback and perceptions on these technologies and further improve their capabilities and potential to better support and deliver organizational needs along the way.

Despite the substantial and significant contributions, the authors would like to acknowledge two limitations of the current study. First, the current study mainly focused on the perceived effectiveness rather the effectiveness itself. A future study which correlate the subjective and objective measures of effectiveness study such as time efficiency through comprehensive usability will be a valuable topic. Second, our study did not correlate the employees' personality to the attitude towards virtual meeting. Future research to incorporate employees' personality will also be a very promising research topic.

\section{Conclusions}

Virtual meetings have been widely utilized during the COVID-19 pandemic [28, 29]. The purpose of this study was to explore the influence of organizational commitment on the perceived effectiveness of virtual meeting by Filipino professionals during the COVID-19 pandemic. A total of 513 Filipino professionals answered an online questionnaire which covered four latent variables: organizational commitment to virtual meetings, attitude toward virtual meetings, perceived effectiveness of virtual meeting as collaboration tool, and perceived effectiveness of virtual meeting as a social tool. SEM was utilized to analyze the causal relationships between the latent variables construct. SEM indicated that organizational commitment to virtual meeting during the COVID-19 pandemic influenced the positive attitude of the employees which subsequently led to the perceived effectiveness of virtual meeting as a collaboration and social tool. This study is one of the first studies that analyzed the influence of organizational commitment on the perceived effectiveness of virtual meeting during the global pandemic Our SEM construct can be applied and extended further, particularly in analyzing factors influencing the perceived effectiveness of virtual meeting during COVID-19.

\section{Conflict of interest}

The authors declare that they have no known competing financial interests or personal relationships that could have appeared to influence the work reported in this paper.

\section{Acknowledgments}

The authors would like to thank all participants in this study.

\section{References}

[1] WHO Coronavirus Disease (COVID-19) Dashboard [Internet]. World Health Organization. World Health Organization; [cited 2021Sep10]. Available from: https:// covid19.who.int/

[2] Laitinen K, Valo M. Meanings of communication technology in virtual team meetings: Framing technology-related interaction. International Journal of Human-Computer Studies. 2018;111:12-22.

[3] Jones RE, Abdelfattah KR. Virtual Interviews in the Era of COVID-19: A Primer for Applicants. Journal of Surgical Education. 2020;77:733-734.

[4] Anderson A, Mcewan R, Bal J, Carletta J. Virtual team meetings: An analysis of communication and context. Computers in Human Behavior. 2007;23:2558-2580.

[5] Lindeblad PA, Voytenko Y, Mont O, Arnfalk P. Organisational effects of virtual meetings. Journal of Cleaner Production. 2016;123:113-123. 
[6] Choi O-K, Cho E. The mechanism of trust affecting collaboration in virtual teams and the moderating roles of the culture of autonomy and task complexity. Computers in Human Behavior. 2019;91:305-315.

[7] Chumg H-F, Seaton J, Cooke L, Ding W-Y. Factors affecting employees' knowledge- sharing behaviour in the virtual organisation from the perspectives of well-being and organisational behaviour. Computers in Human Behavior. 2016;64:432-448.

[8] Presbitero, A. Foreign language skill, anxiety, cultural intelligence and individual task performance in global virtual teams: A cognitive perspective. Journal of International Management. 2020;26:100729.

[9] Presbitero, A. Cultural intelligence (CQ) in virtual, crosscultural interactions: Generalizability of measure and links to personality dimensions and task performance. International Journal of Intercultural Relations. 2016;50:29-38.

[10] Oeppen R, Shaw G, Brennan P. Human factors recognition at virtual meetings and video conferencing: how to get the best performance from yourself and others. British Journal of Oral and Maxillofacial Surgery. 2020;58:643-646.

[11] Porpiglia F, Checcucci E, Autorino R, Amparore D, Cooperberg MR, Ficarra V, Novara G. Traditional and Virtual Congress Meetings During the COVID-19 Pandemic and the Post-COVID-19 Era: Is it Time to Change the Paradigm? European Urology. 2020;78:301-303.

[12] Vo NM, Quiggle GM, Wadhwani K. Comparative outcomes of face-to-face and virtual review meetings. International Journal of Surgery Open. 2016;4:38-41.

[13] Buenaventura RD, Ho JB, Lapid MI. COVID-19 and mental health of older adults in the Philippines: a perspective from a developing country. International Psychogeriatrics. 2020;32:1129-1133.

[14] Prasetyo YT, Castillo AM, Salonga LJ, Sia JA, Seneta JA. Factors affecting perceived effectiveness of COVID19 prevention measures among Filipinos during Enhanced Community Quarantine in Luzon, Philippines: Integrating Protection Motivation Theory and extended Theory of Planned Behavior. International Journal of Infectious Diseases. 2020;99:312-323.

[15] Ocampo L, Yamagishi K. Modeling the lockdown relaxation protocols of the Philippine government in response to the COVID-19 pandemic: An intuitionistic fuzzy DEMATEL analysis. Socio-Economic Planning Sciences. 2020;72.100911.

[16] Arnfalk P, Pilerot U, Schillander P, Grönvall, P. Green IT in practice: virtual meetings in Swedish public agencies. Journal of Cleaner Production. 2016;123:101-112.

[17] Caputo F, Greco A, D“Amato E, Notaro I, Spada S. A Preventive Ergonomic Approach Based on Virtual and Immersive Reality. Advances in Ergonomics in Design Advances in Intelligent Systems and Computing. 2017: 3-15.
[18] Zhang Y, Sun J, Yang Z, Wang Y. Mobile social media in inter-organizational projects: Aligning tool, task and team for virtual collaboration effectiveness. International Journal of Project Management. 2018;36:1096-1108.

[19] Concha D, Romero T, Romero D, Galeano N, Jimenez G, Molina A. Analysis \& Design of a Collaboration Opportunity Characterization Tool for Virtual Organisations Creation. IFAC Proceedings Volumes. 2008;41:1289112898.

[20] Ramos JP, Prasetyo YT. The Impact of Work-Home Arrangement on the Productivity of Employees during COVID-19 Pandemic in the Philippines: A Structural Equation Modelling Approach. 2020 The 6th International Conference on Industrial and Business Engineerin. 2020;

[21] Prasetyo YT, Fuente DGDD. Determinant Factors Affecting Customer Satisfaction among Filipinos in Lazada Online Shopping during COVID-19 Pandemic: A Structural Equation Modeling Approach. 2020 7th International Conference on Frontiers of Industrial Engineering (ICFIE). 2020.

[22] Sarfaraz S, Ahmed N, Abbasi MS, Sajjad B, Vohra F, AlHamdan RS, et al. Self-perceived competency of the medical faculty for E-Teaching during the COVID-19 pandemic. Work. 2020;67(4):791-8.

[23] Abbasi MS, Ahmed N, Sajjad B, Alshahrani A, Saeed S, Sarfaraz S, et al. E-Learning perception and satisfaction among health sciences students amid the COVID-19 pandemic. Work. 2020;67(3):549-56.

[24] Abbott-Gaffney C, Jacobs K. Telehealth in school-based practice: Perceived viability to bridge global OT practitioner shortages prior to COVID-19 global health emergency. Work. 2020;67(1):29-35.

[25] De' R, Pandey N, Pal A. Impact of digital surge during Covid-19 pandemic: A viewpoint on research and practice. International Journal of Information Management. 2020;55:102171.

[26] Hair JF. Multivariate data analysis: a global perspective. Upper Saddle River: Pearson; 2010.

[27] Gefen D, Straub D, Boudreau M-C. Structural Equation Modeling and Regression: Guidelines for Research Practice. Communications of the Association for Information Systems. 2000;4.

[28] Prasetyo YT, Roque RA, Chuenyindee T, Young MN, Diaz JF, Persada SF, et al. Determining factors affecting the acceptance of medical education elearning platforms during the Covid-19 pandemic in the Philippines: UTAUT2 APPROACH. Healthcare. 2021;9(7):780.

[29] Prasetyo YT, Ong AK, Concepcion GK, Navata FM, Robles RA, Tomagos IJ, et al. Determining factors Affecting acceptance of e-learning platforms during the COVID-19 pandemic: Integrating Extended technology Acceptance model and DeLone \& Mclean is success model. Sustainability. 2021;13(15):8365. 